\title{
Jóvenes y juventudes. Acción, representaciones y expectativas sociales de René Unda
}

por Marie-Astrid Dupret

\section{Quito: Abya-Yala}

Por distintos motivos, a veces contradictorios, hablar de los jóvenes es muy de actualidad. En efecto, existe una especie de exaltación de todo lo que remite a la juventud que aparece para algunos como un ideal de vida eterna, fuera de los arrebatos del tiempo, un momento de libertad suprema. Para otros a cambio, este grupo de edad representa una amenaza por no respetar nada e invadir los espacios públicos, con una música ensordecedora que no deja dormir a nadie o cometiendo incivilidades; además son delincuentes en potencia, sobre todo si pertenecen a sectores desfavorecidos...

En este contexto de muchos imaginarios y confusiones, el libro de René Unda es un aporte muy grato que nos permite acercarnos a esta juventud tan paradójica y tan fascinante a la vez. El autor nos presenta los resultados de una investigación de campo llevada adelante entre los años 2007 y 2008, con adolescentes y jóvenes de entre 15 y 29 años (21).

La muestra de la investigación se dividió en 26 grupos, reagrupados en cinco 'tipologías' o categorías (33):

- Jóvenes hijos de migrantes;

- Jóvenes de formas asociativas religiosas;

- Jóvenes de movimientos políticos (juventudes políticas);

- Jóvenes de formas asociativas musicales ('galaxia musical');

- Jóvenes estudiantes.

En cuanto a los temas abordados, éstos giraban alrededor de cuatro ejes: la familia, el sistema educativo formal, el Estado en tanto sistema político y los Medios de comunicación masiva (31). Como lo indica el título del libro, el objetivo de la investigación era entender mejor: "Qué hacen, qué piensan y qué esperan los/las jóvenes?".; y, para el efecto, René Unda trabajó a partir de 
cinco tipos de 'registro de información': Grupos de discusión, grupos focales, entrevistas en profundidad dirigidas a jóvenes y especialistas; relatos de vida y registros de observación (34-35).

A pesar de la gran variedad tanto en los modos de registro como en la procedencia socio-cultural de los jóvenes participantes a la investigación, -y tal vez sea lo más llamativo- los resultados son bastante homogéneos y relativamente coincidentes, a pesar de la diversidad de las escuchas. A cambio, sería interesante reflexionar más sobre el sentimiento de ruptura generacional, ya que, como lo nota René Unda, "la hipótesis de que las brechas entre 'mundos juveniles' y espacios formales institucionales es cada vez mayor parece verse suficientemente apoyada a la luz de las narrativas de los jóvenes" (36).

No intentaremos resumir los resultados de este trabajo minucioso que brinda un motón de informaciones muy diversas, limitándonos a mencionar los principales aportes a nuestro parecer, unos en la medida que corroboran estudios de la literatura científica sobre la juventud, otros en cuanto complementan aquellos con reflexiones más personales que subrayan el frecuente sentimiento de desorientación de las nuevas generaciones en medio de la globalización sociocultural del mundo neo-liberal -si es que se puede hablar todavía de socioculturas y no de simples vestigios de organizaciones desagregadas bajo los efectos de la posmodernidad y del individualismo extremo.

Más allá de los grandes ejes de la investigación, las opiniones de los jóvenes encuestados nos parecieron particularmente significativas respecto a tres cuestiones. Por un lado, el anhelo de una verdadera familia, de una familia que asuma responsabilidades, en particular en lo que concierne la autoridad y los valores culturales, es un punto notable. Por otro lado, muchas de las opiniones de los jóvenes parecen atravesadas por la paradoja de una exigencia de individualización forzada precisamente cuando el lugar del sujeto en el tablero del mundo está marcado por un gran interrogante, mientras que las estructuras colectivas están desapareciendo. Por fin, se vislumbra una relación ambivalente, a la vez de desinterés y de expectativas, con la política y la institucionalidad en general, ligada a la frecuente demisión de los adultos, políticos o profesores.

En los comentarios de los jóvenes sobre la familia, tema muy documentado en la investigación, se hubiera esperado respuestas mucho más variadas conforme a la multiplicidad de los discursos sobre esta cuestión en la actualidad. 
Sin embargo, como lo nota René Unda (89), para todos los encuestados, si bien consideran que la familia está 'desarticulada' o en 'crisis', existe una valoración muy elevada de esta institución, como el lugar ideal del respaldo al adolescente, y cuyo fortalecimiento está claramente deseado. En otras palabras, se da la impresión que la juventud aboga por un modelo de familia tradicional que le sirva de protección pero también de contención, por ejemplo contra el libertinaje; así como lugar supuesto de transmisión de 'valores y reglas' $(84,90,112 \ldots)$, en cuyas falta insisten repetidamente. A la vez se perfila de manera recurrente la importancia insustituible del dinero en la vida, sin que los jóvenes adviertan cierta contradicción, o por lo menos la distinción esencial entre el valor del dinero y los valores éticos.

Como lo escribe con fineza el autor: "Liberado el sujeto a las fuerzas del mercado, el entramado de vínculos tiende a mostrarse cada vez más penetrado y configurado por transacciones económico-monetarias más que por relaciones de socializad. Se produce, así, un nuevo tipo de individualidad en el que su reconocimiento en la sociedad se vuelve difuso y opaco" (117-118). En este contexto, la valoración prioritaria del dinero desemboca en una individualización basada en rasgos imaginarios que sirven para indicar la posesión de bienes materiales como condición del reconocimiento social, lo que conlleva a "la despolitización [...], como uno de los efectos de la de-socialización mercantilista”. Y son los mismos jóvenes que se quejan de la pérdida de la amistad, de la demisión de los profesores o de los políticos, sin percatarse en absoluto de las causas de una situación que, a la larga, destruye sus propias condiciones de vida socio-cultural.

Los aportes de esta investigación son numerosos y significativos. Sin embargo, a veces uno puede pensar que el trabajo no agotó sus posibilidades; de ahí dos observaciones. La primera se refiere a la ausencia de un análisis del lugar de "las representaciones y expectativas sociales" en la mente de los jóvenes, y por ende de las relaciones entre el pensamiento y las ideas por una parte, y su manera de actuar por la otra (notaremos que la palabra 'acción' aparece en el título, sin que se aborde este tema); además no se aprecia la construcción de una imagen de sí mismo y tampoco de una proyección a futuro sino de manera muy anecdótica. Esta puesta de lado de las cuestiones más psíquicas se reflejan en el uso del término de subjetividad (41ss) que crea cierta ambigüedad, a partir del 
presupuesto que uno es lo que dice ser, y que su comportamiento es conforme a lo que quiere expresar, sin reconocer la influencia predominante de las experiencias de vida y, sobre todo, de los discursos de moda, en las elecciones de los modelos identificatorios y en las maneras de actuar.

La segunda observación remite a una cuestión más metodológica, aunque complementa la anterior. Luego de la lectura del texto, se tiene la sensación de mucho material de gran interés pero uno queda perplejo en cuanto a los jóvenes mismos, como si quedaran difuminados y refractados en distintos grandes temas sin que se pueda darles un rostro singular. Tal vez - no sería complicado remediar a esto ya que cada uno puede proceder a esta aproximación por su cuenta- hubiera sido provechoso presentar, después de la investigación, retratos más profundizados de cada uno de los grandes tipos de jóvenes del estudio, que permitan al lector unir los datos dispersos en cada capítulo: ¿Habría una relación especial del Rockero con cierta demanda política y cierto tipo de relación familiar? ¿Será que el joven religioso, a pesar de ser muy conformista, tiene un punto de vista original sobre la educación?

A pesar de estas observaciones, el libro de René Unda es un trabajo muy serio que abre el camino hacia investigaciones originales. En especial, intriga el tema de los jóvenes pertenecientes a grupos musicales que no deja de ser muy poco estudiado en su complejidad: ¿Por qué opta un joven por tal o cual grupo? ¿Existen ciertas afinidades? .... O ¿ es solamente una cuestión de azar? ¿Se consideran como Tribus urbanas, en el mismo plan que los Emos u los Góticos?

En fin, la lectura del libro de René Unda no sólo es muy sugestiva sino que anima a quien está preocupado por las cuestiones de infancia y adolescencia, y más allá en todo lo que remite a una apreciación de la sociocultura y del devenir humano a buscar nuevas pistas de reflexión, nuevos senderos de estudio, con el fin de proponer algunas soluciones a los problemas más acuciantes del mundo actual que, sin lugar a duda, golpearan con más fuerza aun a las generaciones del futuro. 